\title{
Pierre Dumont, La francophonie autrement. Héritage senghorien? Et si le Faire l'emportait sur le Dire...
}

\section{Luigia Pattano}

\section{(2) OpenEdition}

1 Journals

\section{Edizione digitale}

URL: http://journals.openedition.org/studifrancesi/8388

DOI: 10.4000/studifrancesi.8388

ISSN: 2421-5856

\section{Editore}

Rosenberg \& Sellier

\section{Edizione cartacea}

Data di pubblicazione: 1 mai 2009

Paginazione: 215-216

ISSN: 0039-2944

\section{Notizia bibliografica digitale}

Luigia Pattano, «Pierre Dumont, La francophonie autrement. Héritage senghorien? Et si le Faire l'emportait sur le Dire...», Studi Francesi [Online], 157 (LIII | I) | 2009, online dal 30 novembre 2015, consultato il 11 janvier 2021. URL: http://journals.openedition.org/studifrancesi/8388 ; DOI: https://doi.org/10.4000/ studifrancesi.8388

Questo documento è stato generato automaticamente il 11 janvier 2021.

\section{(c)}

Studi Francesi è distribuita con Licenza Creative Commons Attribuzione - Non commerciale - Non opere derivate 4.0 Internazionale. 


\title{
Pierre Dumont, La francophonie autrement. Héritage senghorien? Et si le Faire l'emportait sur le Dire...
}

\author{
Luigia Pattano
}

\section{NOTIZIA}

PIERRE DUMONT, La francophonie autrement. Héritage senghorien? Et si le Faire l'emportait sur le Dire..., Paris, L’Harmattan, 2008 («Critiques littéraires»), pp. 246.

1 Obiettivo dichiarato del lavoro di Pierre Dumont, celebre linguista e docente universitario che ha collaborato a lungo, in qualità di esperto, con le istituzioni francofone, è mostrare un altro modo di vedere e di vivere la francofonia, che consentirebbe per una volta la vittoria dell'agire sul parlare, a partire dalla rilettura delle idee di quello che egli considera uno degli iniziatori di una nuova concezione di Francofonia: Léopold Sédar Senghor. Mettendo da parte - senza dimenticarle - le critiche spesso ingiuste rivolte al poeta, Dumont riconosce a questi il merito di aver messo in luce la centralità, in ambito francofono, di una politica culturale fondata su un approccio pedagogico e didattico alle questioni linguistiche che può essere riassunta in alcuni termini chiave - anche se creati più tardi - quali «partenariato linguistico» (lanciato per la prima volta nel 1995 a Cotonou da Abdou Diouf, attuale segretario generale dell'OIf, che ha scritto la prefazione al volume) e «pedagogia della convergenza». Quest'ultima, auspicata da Dumont, poggia su una concezione pragmatica dello studio della lingua, attenta al contesto sociale e culturale in cui sono collocati i locutori, e caldeggia il ricorso al bilinguismo in ambito didattico per favorire lo sviluppo dell'individuo.

2 Testo eterogeneo che riunisce vari contributi sui temi della Francofonia, il volume si suddivide in tre sezioni. La prima («Témoignages») presenta, accanto a una parte dal tono intimistico legata alla vita dell'autore, il testo di una conferenza tenuta nel 2001, 
nella quale Dumont proponeva di pensare la Francofonia in un modo nuovo che si fondi sul riconoscimento della varietà delle situazioni in cui il francese può essere usato. Questa sezione riporta il testo del discusso manifesto Pour une littérature-monde, apparso su «Le Monde» del 16 marzo 2007 - manifesto a cui Dumont e Confiant rimproverano il tono demagogico e una visione falsa della situazione linguistica che porta, secondo i firmatari, alla morte della vecchia Francofonia - , e il controverso discorso pronunciato nel 2007 da Sarkozy a Dakar. Le parole del presidente della Repubblica francese sono aspramente criticate da Dumont, in quanto denotano scarsa conoscenza del contesto culturale africano e assenza di riferimenti ai lavori condotti da équipes franco-africane sui bisogni reali degli individui in fase di apprendimento, per non parlare del tono da «donneur de leçons» con cui il presidente auspica, in termini eurocentrici, una «Renaissance» africana.

Le altre due sezioni sono invece dedicate a temi più prettamente linguistici. Nella parte intitolata «Métissagge impossible», Dumont affronta le questioni e i problemi relativi all'apprendimento del francese come lingua straniera e avanza suggerimenti intesi a evitare i conflitti e l'insicurezza generati dal predominio di un'unica lingua sulle altre, quali il riconoscimento, in una prospettiva interculturale, delle norme linguistiche proprie di un dato paese o di una data regione e delle diverse varietà di francese. In quest'ottica rivaluta anche la controversa posizione linguistica di Senghor che avrebbe avuto, in ogni caso, il merito di porre la lingua al centro del dialogo e del meticciato culturale fondato sulla reciproca comprensione. Lo studio della lingua non può quindi prescindere dall'osservazione e dal riconoscimento delle specificità culturali altrui: «L'interculturel ne doit pas se limiter à une simple volonté de "tolérer" l'autre, mais se définir comme une aptitude à comprendre sa différence, comme sa ressemblance, dans un esprit de "convergence conscientisée"» (p. 165).

La questione identitaria legata alla lingua è ripresa nell'ultima sezione («Langue et pouvoir») attraverso le nozioni di comunità linguistica e di lingua-cultura. Dumont lamenta la scarsa importanza accordata alle questioni linguistiche nella costruzione della Francofonia e la mediocre considerazione di cui godono, in ambito istituzionale, gli esperti chiamati a indicare le linee guida delle politiche educative. L'avviamento del «partenariat linguistique» auspicato da Diouf nel 1995 rappresenterebbe per Dumont una sorta di rivoluzione tranquilla fondata su un'identità che si definisce al contempo come radicamento e come apertura. 